\title{
Emancipating lenes
}

\section{A reanalysis of English obstruent clusters}

\author{
Péter Szigetvári \\ Eötvös Loránd University, Budapest \\ szigetvari@elte.hu
}

\begin{abstract}
I argue that English has no voicing assimilation, in fact, it does not have phonologically voiced segments at all. Voicing in English is spontaneous in sonorants, while obstruents may be phonetically voiced only if lenis and surrounded by spontaneously or passively voiced sounds. The paper claims that most obstruent clusters of English are traditionally misanalysed as fortis+fortis clusters. These clusters are all either fortis+lenis or lenis+fortis; in fact, fortis+fortis clusters are completely ruled out in English.
\end{abstract}

Keywords: English; obstruent clusters; fortis; aspiration; plural/past suffix allomorphy

English ${ }^{1}$ is full of obstruent clusters that agree in "voicing", such that both members are "voiceless". Examples include actor, raptor, act, apt, scam, mask, next, after, raft. I argue that while these words indeed contain obstruent clusters of two or three phonetically voiceless obstruents, none of the clusters are made up of exclusively fortis consonants. That is, they are all misanalysed in the current descriptive practice: actor is, in fact, [agtə], scam is [sgam], etc. Two fortis obstruents may simply not be adjacent in English. The views presented in this paper have been aired earlier by, e.g., Twaddell (1935); Jones (1967); Davidsen-Nielsen (1969); Cyran (2014). I am here driving the idea through the laryngeal phonology of English. Many consequences remain to be catalogued.

I briefly introduce the distinction between voicing and aspirating languages in $\S 1$. I then show some suspicious statistics about the frequency of fortis vs. lenis obstruent clusters, which suggests that our current interpretation of these clusters is a result of misanalysis (§2). Next I argue that the past and the plural suffix does not undergo voicing assimilation in English (§3). The absence of $[\mathrm{s}]+$ aspirated plosive clusters is discussed

1 "English" in this paper means current British English, the post-RP reference accent of England. As far as I can tell, the claims I'm going to make hold for other varieties too, most notably General American. There are certainly varieties, also referred to as "English", whose laryngeal phonology is different. 
in $\S 4$, followed by the main proposal of the paper: fortis consonants cannot be adjacent in English ( $(5)$. A potential problem to the analysis is raised in $\S 6$, and conclusions are offered in $\S 7$.

\section{Laryngeal contrasts}

English has two sets of obstruents, the textbook labels for which are "voiceless" and "voiced", since the symbols used to represent them are defined as such in the IPA. It has been clear for quite a long time though that the difference between the members of the two sets is not primarily in voicing, but in other phonetic correlates, like aspiration, shortening of the preceding sonorant interval, and strength of articulation (Harris 1994; Iverson \& Salmons 1995; Honeybone 2002; Beckman et al. 2013). The last correlate was encoded in earlier terms for this opposition: fortis and lenis (Sievers 1876), or tense and lax (Jakobson et al. 1952). Languages that contrast voiceless and voiced obstruents (like Warsaw Polish or Hungarian) are called voicing languages, others that contrast prevocalic obstruents by aspiration (like English or Mandarin) are called aspirating languages.

However, the types of phonetic contrasts between obstruent pairs are not enough to determine that English is not a so-called voicing, but an aspirating language (Cyran 2014). Rather, this decision must be based on phonological behaviour. In a voicing language, voiced obstruents contain some theory-specific exponent of voicing, the feature [voiced] or the element L in Element Theory (Kaye et al. 1985; Harris \& Lindsey 1995; Backley 2011), while voiceless ones do not contain any laryngeal specification. On the contrary, in an aspirating language it is "voiced", that is, lenis obstruents that are unspecified, and "voiceless", that is, fortis ones are marked by the feature [spread glottis] or ET's element H. Now it is an obvious conclusion that voicing assimilation is expected to occur only in a voicing language, but not in an aspirating language, in which there is no phonological prime causing voicing. In Hungarian an obstruent, here [p], is voiced when followed by a voiced obstruent: népdal [ne:bdal] 'folk song', népzene [ne:bzene] 'folk music' (the spelling indicates the "underlying" form of the morphs). However, we do not find voicing before sonorants: népének [ne:pe:nek] 'religious folk song', néprajz [ne:prajz] 'ethnography', népmese [ne:pme e] 'folk tale'. Voicing of obstruents is a change of categories: készpénz ${ }^{2}$ [ke:spe:nz] 'ready money', i.e., 'cash', is phonetically

${ }^{2}$ The digraph $\langle\mathrm{sz}\rangle$ represents $[\mathrm{s}],\langle\mathrm{s}\rangle$ is $[\mathrm{f}]$. 
identical to kézpénz 'hand money', ${ }^{3}$ and készból [ke:zbøl] 'from ready' is phonetically identical to kézból 'from hand'.

In English, on the other hand, the laryngeal category of obstruents is never changed by the following segment, be it a sonorant or an obstruent: uprise [əprajz], ${ }^{4}$ upmost [əpməwst], update [əpdejt] (I will return to apparent counterexamples in $\S 3$ ). This fact is evidence that neither sonorants, nor (lenis) obstruents contain any feature that could spread and make the preceding obstruent phonologically voiced. Thus the difference between Hungarian $([\mathrm{pd}] \rightarrow[\mathrm{bd}]$ in népdal) and English $([\mathrm{pd}] \not \rightarrow[\mathrm{bd}]$ in update) is ascribed not to the presence vs. absence of some voice assimilation rule, but to the presence vs. absence of a feature or element: Hungarian has [voiced]/L, English does not. One might expect then that since in English the "fortisness" feature [spread glottis]/H is available in obstruents of the language, it could perhaps spread in obstruent clusters (cf. Balogné Bérces \& Huszthy 2018 for arguments that this is a valid expectation). However, [spread glottis]/H does not spread either (cf. §3): bagpipe and backpipe, backfire and bagfire are not homophonous pairs (in the kind of English discussed in this paper).

Lenis obstruents in English may be phonetically voiced, that is, the vocal folds may vibrate throughout the pronunciation of an obstruent. For this to occur they must be both followed and preceded by sonorants (cf., e.g., Cruttenden 2014, 164) or other lenis obstruents which in turn are preceded/followed by a sonorant or other lenis obstruents (Jansen 2004). This kind of voicing, called passive voicing, is very different from what we see in a voicing language, where an obstruent may be voiced "on its own right". ${ }^{5}$

There are very few instances in English where the laryngeal category of an obstruent - always a fricative - changes. In a closed class of noun stems the final fortis fricative is lenis in the plural (e.g., knife $\sim$ knives). In a closed class of verb stems the final lenis fricative appears to be fortis in the

${ }^{3}$ In fact, many confuse the two in spelling, since 'hand money' is also a plausible semantic analysis for 'cash'.

${ }^{4}$ In this paper (British) English vowels are transcribed using a rather simple set of symbols, [i e a ə o u]. My transcriptions also suggest that the so-called diphthongs are in fact $\mathrm{VC}$ sequences. Nothing of importance hinges on this decision, the reader may safely replace these symbols with any others of their preference.

${ }^{5}$ Fricatives behave differently from plosives in this respect, prevocalic fricatives may exhibit significant voicing even without a preceding sonorant or lenis (Jansen 2004). The fact that a following vowel is enough to voice a fricative, but not a plosive may have a phonetic explanation, which I do not address here. 
past tense (e.g., leave $~$ left; however, I will show below, that no change of laryngeal category occurs here) ${ }^{6}$ In a small set of semantically and phonetically related stems the noun/adjective ends in a fortis, the verb/adjective in a lenis fricative (e.g., teeth $\sim$ teethe, life $\sim$ live, use [juws] $\sim$ [juwz], close [kləws] $\sim[k l ə w z])$. Finally, in some noncoronal plosive+coronal fricative clusters the fricative is fortis before an unstressed vowel and lenis before a stressed one (e.g., execute [éksəkjuwt] executive [əgzékjətiv]. ${ }^{7}$

The important phonetic cue in distinguishing word-final obstruents following a stressed vowel is the length of the preceding vowel(+sonorant consonant sequence). In a word-final stressed syllable the length of a prefortis vowel may be about half of the length of its prelenis counterpart (Cruttenden 2014; Kaye 2014). Accordingly, the length of [owl] is greater in cold than in colt, and [en] is longer before the lenis [z] in tens than before the fortis [s] in tense (cf. Wells 2008). This length difference also holds when the sequence before the fortis involves a lenis obstruent, like in width [wid $\theta$ ] vs. with [wið] or in Hudson [hədsən] vs. Pudsey [pədzij]. Apparently, the shortening occurs whenever a vowel is followed by a fortis obstruent before the next vowel, no matter what consonants (sonorants and lenis obstruents) intervene. That is, it is not a lenis consonant that makes the preceding sonorant sequence longer, but a fortis consonant that makes it shorter (hence the name "prefortis clipping", not "prelenis lengthening").

\section{Suspicious statistics}

I have counted standalone obstruents, that is, obstruents that are not adjacent to another obstruent, but either to sonorants (including vowels) or to a sonorant and the edge of the word, in English. ${ }^{8}$ The figures are shown in (1), where "plos." also includes the two affricates.

We see that the frequency of standalone fortis and lenis obstruents is in the same order of magnitude, in most cases their ratio is less than $2: 1$. Extreme ratios occur in the case of fricatives. Word initially lenis fricatives

${ }^{6}$ The same holds for plosives in some verb/noun pairs, like describe $\sim$ description, I will argue below that this is also apparent: the labial plosive is lenis in both words.

${ }^{7}$ Here I transcribed the first word with [ks], according to the mainstream practice. I will argue that this cluster is, in fact, [gs], i.e., it is only the fricative that alternates.

8 The count is based on the database of CUBE (Lindsey \& Szigetvári 2013-), an online searchable pronunciation dictionary containing over 100000 entries. This corpus aims at being representative of the vocabulary of English. It contains inflected forms and about $17 \%$ of the entries are names, which potentially feature odd phonotactics. 
(1) Standalone obstruents (in thousands) in English

\begin{tabular}{|c|c|c|c|c|c|c|c|c|c|c|c|c|}
\hline & \multicolumn{3}{|c|}{ word-initial } & \multicolumn{3}{|c|}{ word-medial } & \multicolumn{3}{|c|}{ word-final } & \multicolumn{3}{|c|}{ all } \\
\hline & fortis & lenis & ratio & fortis & lenis & ratio & fortis & lenis & ratio & fortis & lenis & ratio \\
\hline plos. & 23.7 & 17.7 & 1.3 & 41.5 & 28.6 & 1.5 & 11.0 & 9.3 & 1.2 & 76.2 & 55.6 & 1.4 \\
\hline fric. & 14.5 & 2.2 & 6.8 & 23.6 & 11.2 & 2.1 & 6.9 & 16.6 & .4 & 45.0 & 30.0 & 1.5 \\
\hline all & 38.3 & 19.8 & 1.9 & 65.0 & 39.8 & 1.6 & 17.8 & 25.9 & .7 & 121.2 & 85.6 & 1.4 \\
\hline
\end{tabular}

are relatively rare for historical reasons, while word finally they outnumber their fortis counterparts. As expected, word initially the marked fortis, word finally the unmarked lenis obstruents are more common. All in all there are $42 \%$ more standalone fortis than lenis obstruents.

The situation is very different if we look at obstruent clusters. The data in (2) summarize two-member clusters, longer obstruent clusters are less common and even more unbalanced. I include morphologically complex forms (past, plural, and compounds) too. Although this may introduce some distortion in the numbers, it does not significantly modify the ratios.

(2) "Laryngeally uniform" two-member obstruent clusters

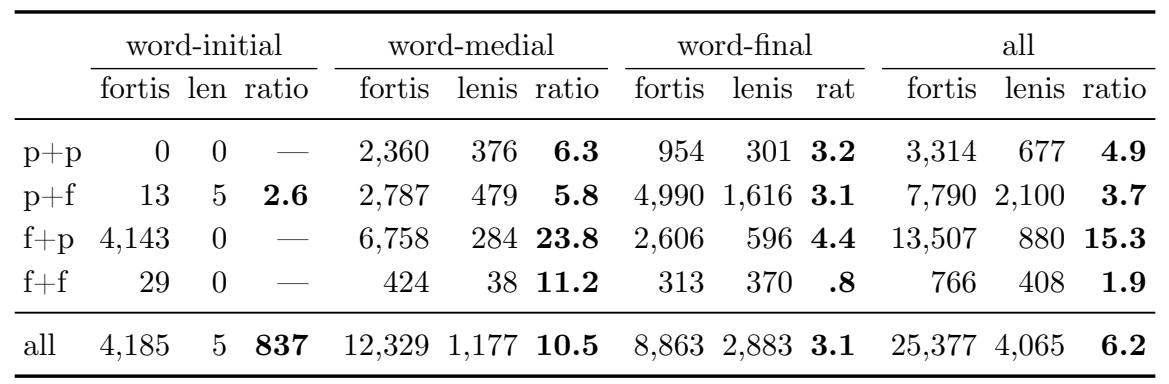

Word initially we practically find only fortis clusters (e.g., Dvorak is a rare case of lenis). Word medially fortis clusters are ten times more frequent than lenis, and even word finally fortes strongly outnumber lenes, despite the predominance of lenes in this position in the case of singleton obstruents, cf. (1). Overall there are more than six times more fortis than lenis clusters. This huge discrepancy in the ratio of the frequency of singleton fortis and lenis obstruents and that of clusters containing fortes and lenes requires some explanation, especially since unexpectedly the balance tilts strongly towards the marked pole of the contrast, fortis. 


\section{Laryngeal assimilation}

I have not mentioned clusters containing a fortis and a lenis obstruent in $\S 2$. There are only a few hundred such clusters in the CUBE database (631 fortis+lenis and 886 lenis+fortis), and the large majority of these occur across a word boundary in a compound word. It is again suspicious that although English does not exhibit laryngeal assimilation in obstruent clusters, fortis + fortis and lenis+lenis clusters dominate the scene, within a morpheme the other two types appear to occur only before a stressed vowel (at a foot boundary): e.g., disdáin, Áztèc.

Descriptions of English discuss two sets of single-consonant suffixes, which allegedly undergo laryngeal assimilation. These are the verbal past tense and past participle [d] (I'll call it the D suffix) and the verbal 3sg present, nominal plural and genitive $[\mathrm{z}]$, which are homophonous with a cliticized form of the auxiliaries is and has (I'll call these the $\mathrm{Z}$ suffix, even when a clitic). The third single-consonant suffix, the nominalizing and ordinal $[\theta]$ does not assimilate, but it is claimed to induce assimilation in, e.g., twelfth.

It is commonly assumed that the $\mathrm{D}$ and the $\mathrm{Z}$ suffix assimilate to a word-final fortis obstruent, resulting in transcriptions like kicked [kikt], kicks [kiks], or it's [its] (but see Jones 1967, §171ff for the alternative view to be presented here). Harris $(1994,137)$ clearly suggests that the $\mathrm{H}$ element (i.e., the fortisness) of the stem-final obstruent spreads on the suffixal consonant. This analysis is not plausible for several reasons. H-spreading in the D and Z suffixes would be the only case of laryngeal assimilation in English. Furthermore, we would not encounter this effect within a morpheme (e.g., Leipzig [lajpzig]), but we would across a strong boundary (e.g., wipes it [wajpsit]), even across a word boundary (e.g., Depp's a pirate [depsə-] $<$ [dep əz ə-]). This is a rather unlikely configuration typologically. It is true that the suffix in kicked and kicks is phonetically voiceless, however, a voiceless obstruent in an aspirating language is not necessarily fortis. As Cyran $(2014,203)$ argues, passive voicing does not occur in the environment of a fortis obstruent. Accordingly, there is no reason to distinguish the laryngeal category of the fricative in Leipzig [lajpzig] and wipes it [wajpz it]. ${ }^{9}$

${ }^{9}$ Note that even a spontaneously voiced sonorant is voiceless in this position in languages that afford this configuration, e.g., French peuple [pœpl] 'people' or Polish wiatr [vjatr] 'wind'. 
This proposal has far-reaching consequences. On the one hand, both the $\mathrm{D}$ and $\mathrm{Z}$ suffixes "lose" one of their allomorphs, $[\mathrm{t}]$ and $[\mathrm{s}]$, respectively. ${ }^{10}$ This is a welcome development, it makes the description of the allomorphy of these suffixes simpler. The D suffix has a vowel-initial allomorph after [t] and [d], and a uniform [d] elsewhere, the Z suffix has a vowel-initial allomorph after a sibilant-final stem, and a uniform $[\mathrm{z}]$ elsewhere: rigged [rigd], kicked [kikd], tabs [tabz], taps [tapz]. In addition, the proposal leads to thousands of new cases for obstruent clusters with dissimilar laryngeal specifications, i.e., this turns out not to be a special occurrence in English. At the same time it reduces the frequency of word-final fortis obstruent clusters.

\section{A not so new solution for an old problem}

It is a well-known niche of the phonology of English that plosives are not aspirated after $[\mathrm{s}]$. So while the $[\mathrm{p}]$ in pen, percent, append, or open is more or less aspirated, that in spend, spaghetti, suspend, or aspen is not aspirated at all. ${ }^{11}$

Two types of explanations were offered for the absence of aspiration after $[\mathrm{s}]$. One stipulates that for a plosive to be aspirated, it must be syllable initial. A word like suspend may in theory have three possible syllabifications: (i) su.spend, (ii) sus.pend, and (iii) susp.end. Syllabification (i) violates the Sonority Sequencing Principle (Lowenstamm 1981; Selkirk 1984; Clements 1990) if we accept a detailed sonority scale, in which the fricative $[\mathrm{s}]$ is more sonorous than the plosive [p]. Syllabification (iii) violates the Onset Maximization Principle (Kahn 1976) in having a consonant-final syllable followed by a vowel-initial one. Only syllabification (ii) satisfies the two basic syllabification principles, but in it the plosive is syllable initial, yet it is not aspirated. A common way to posit su.spend and avoid the sonority violation is to go for a less detailed version of the sonority scale, in which all obstruents are equal in sonority (Clements 1990; Zec 1995). Accordingly, sonority does not fall at the beginning of the putative

${ }^{10}$ In fact, both these allomorphs exist, but they only occur in irregular morphology: burnt, spelt, left, pence.

${ }^{11}$ According to common wisdom, a plosive followed by an unstressed vowel is not aspirated. Some measurements show otherwise. Here are some mean VOT values in ms from the speech of a young male "standard British" speaker (the plosive in question is capitalized): Paces 54, piPer 36; Table 75, wriTer 80; Cable 56, hiKer 55 (G. Kiss 2017). 
syllable [spend], but remains level. In this case, we have to explain at least two things: why other clusters of two obstruents, i.e., level sonority, like [ft], [ps], or [pt], do not occur in what is considered syllable-initial position (note that the $[\mathrm{t}]$ is aspirated in baptize) and why aspiration occurs syllable initially of all positions. ${ }^{12}$ More seriously, this attempt fails to account for the absence of aspiration after fortis fricatives other than [s], e.g., in after or Pashto. Although Kahn (1976) would accept the syllabification a.fter, most other proponents of this analysis would not, since they subscribe to the idea that any word begins with a syllable onset (e.g., Blevins 1995, 209), ${ }^{13}$ and only $[\mathrm{s}]+\mathrm{C}$ clusters occur word initially, $[\mathrm{f}]+\mathrm{C}$ and $\left[\int\right]+\mathrm{C}$ do not (or if they do, like in schtick, that does not seem to matter). I claim that the difference between mistake [mi'stejk] and mistime [mis'tajm] is not one of syllabification, as suggested by the transcription in dictionaries, but one of a synchronically visible morpheme boundary vs. its absence. That is, the [t] of mistime is aspirated just like that of miss thyme.

The other explanation for the absence of aspiration after fortis fricatives is articulatory. Iverson \& Salmons $(1995,371)$ quote Kim:

\section{"if the glottis is instructed to open to the same degree and for the same period for $/ \mathrm{p} /$ of $/ \mathrm{sp} /$ as it would for initial $/ \mathrm{p} /$, the glottis will begin to close by the time the closure for $/ \mathrm{p} /$ is made, and consequently, by the time $/ \mathrm{p} /$ is released, the glottis will have become so narrow that the voicing for the following vowel will immediately start, and thus we have an unaspirated /p/ after /s/" $(1970,114)$}

If the glottis begins to close earlier in spend than in pen, relative to the [p], then this must be because the $[\mathrm{p}]$ of spend does not contain any instruction for keeping the glottis spread; if it did, the glottis would have to remain spread during the articulation of $[\mathrm{p}]$. In other words, this plosive is not fortis, but lenis. It is, nevertheless, voiceless, since it is preceded by a fortis obstruent. This means that spend is $[\mathrm{s}]+$ bend. The idea that the second segment of $[\mathrm{s}]+$ plosive clusters might be analysed as lenis is not new, it has been suggested by Twaddell (1935) and argued for extensively by Davidsen-Nielsen (1969). Such an analysis provides a trivial explanation for the absence of aspiration after fortis fricatives: these plosives are always lenis. To be precise, aspirated plosives do occur after voiceless fricatives, which must then themselves be lenis, in some cases spelled and trancribed as such (cf. (3b)), in other cases spelled and/or transcribed as if they were

${ }^{12}$ I am not claiming that there is no plausible explanation, but proponents of this analysis rarely elaborate on it.

${ }^{13}$ Note that having the $[\mathrm{s}]$ in an appendix is no good, since the following plosive is then at the beginning of the syllable. 
fortis (e.g., cosplay [kozplej], lieutenant [leftenənt], which accordingly is [levtenənt]).

At this point we have the three types of fricative+plosive clusters exemplified in (3).

\section{(3) Types of fricative + plosive clusters}

a. lenis+lenis: husband [həzbənd], wisdom [wizdəm], Glasgow [glazgəw]

b. lenis+fortis: gazpatcho [gazpatfəw], Aztec [aztek], Azkaban [azkəban]

c. fortis+lenis: aspen [asbən], after [afdə], Afghan [afgan], Oscar [osgə]

A fortis fricative may only precede a fortis plosive across a strong boundary, as in mis\#time, brief\#case, tooth\#pick. So an aspirated plosive may occur after a fricative only if (i) they are separated by \#, as in mistime, (ii) the fricative is lenis as in Aztec, or (iii) both, as in Jamestown. No syllable boundaries are ever involved in the distribution.

\section{5. *Fortis+fortis}

An explanation of the absence of aspirated plosives after a fortis fricative requires a further step. We posit a general phonotactic constraint for English: *fortis +fortis $\left({ }^{*} \mathrm{FF}\right)$. That is, not only a fortis fricative may not be followed by a fortis plosive, but no two fortis obstruents may ever be adjacent within a morpheme in English. Here we do not investigate the reason why fortisness may characterize a span of maximally a single segment at a time, ${ }^{14}$ but we will look at some consequences, pointing out the advantages of the adoption of such a constraint.

We have shown in $\S 2$ that while the frequency of standalone fortis and lenis obstruents is on a par, FF clusters vastly outnumber all of the types which include lenes. This is suspicious, since in state-of-the-art analyses fortis is the marked pole of this contrast. The rarity of lenis + fortis (LF) and fortis+lenis (FL) clusters is also unexpected in a language that does not exhibit laryngeal assimilation. In the current view, however, all monomorphemic obstruent clusters earlier counted as FF are either LF or FL. The absence of clusters consisting of two marked fortes is more plausible than its overwhelming frequency.

It is not trivial, however, to decide if a given cluster is LF or FL. Plosive-final clusters are often disambiguated by aspiration: Aztec or naiveté

${ }^{14}$ Several such fortis spans may occur within a morpheme (e.g., carpet, south) provided that they are separated by a span of nonfortis segments. 
[najijvtej] have aspirated [t], hence LF clusters, while aster [asdə] or after [a:fdə] have an unaspirated plosive, i.e., [d], in FL clusters. Word finally, however, the difference between LF and FL seems to be neutralized. Earlier (§3) we claimed that past tense forms uniformly end in [d] in English, tracked is [trakd]. The homophonous noun tract is better analysed as [tragt], with the same cluster as the etymologically related tractate [tragtejt], in which the aspiration of the middle [t] reveals its fortisness. What justifies the different analyses is the observation that changes from fortis to lenis or vice versa do not abound in English. Thus it is reasonable to assume that the velar plosive does not change either in [trak] [trakd] or in [tragtejt] $\sim$ tragt]. The vowel of both words is shortened by the fortis plosive that follows it: $[\mathrm{k}]$ in [trakd], [t] in [tragt]. The intervening lenis consonant has no effect on this, just like the intervening sonorant does not inhibit shortening in tramp. Accordingly, we see a change only in the spelling of twelve [twelv] twelfth [twelv $\theta$ ], the morpheme-final fricative - though phonetically voiceless - does not turn into fortis. ${ }^{15}$

\section{An apparent problem}

Most varieties of English restrict the occurrence of nasal+lenis plosive clusters, so that the noncoronal tokens occur only before a vowel or approximant. Examples are shown in (4). ${ }^{16}$ The gaps in (4c), ${ }^{*}[\mathrm{mpw}]$ and *[mbw] (as well as *[ntj] and *[ndj] for many speakers) are due to independent constraints. All other combinations are available in (4a-e). When the nasal+plosive cluster is word final, the noncoronal lenis clusters are missing, cf. (4f). When followed by a nasal or a fricative, all lenis clusters are missing, cf. $(4 \mathrm{~g}-\mathrm{h})$. When followed by a plosive, only the fortis noncoronal clusters are available, cf. (4i).

My hypothesis predicts that the two types in (4i) do not exist: [mpt] and $[\mathrm{nkt}]$ violate ${ }^{*} \mathrm{FF}$. Reanalysing these as $[\mathrm{mpd}]$ and $[\mathrm{nkd}]$ is not viable, because the plosive at the end of these clusters is aspirated, even if rather

${ }^{15}$ We assume a similar analysis for leave $\sim$ left [levt] or lose $\sim$ lost [lozt] (with the irregular [t] allomorph of the D suffix) vs. leafed [lijfd] or used [juwzd] (with the regular [d] allomorph).

${ }^{16}$ In standard spelling: simple, timber, winter, hinder, tinker, finger, ampule, ambulant, contuse, Honduras, vinculum, angular, Antwerp, conduit, banquet, language, empress, membrane, entry, hundred, synchrony, angry, templar, emblem, antler, chandler, franklin, angler, lamp, ant, hand, ink, company, centner, splanchnic, glimpse, chintzy, sphynx, empty, sphincter. 
(4) Nasal+plosive clusters

\begin{tabular}{|c|c|c|c|c|c|c|c|}
\hline & & $\mathrm{mp}$ & $\mathrm{mb}$ & nt _ & nd__ & $\mathrm{yk}$ & $\mathrm{yg}$ \\
\hline a. & $-\mathrm{V}$ & simpəl & timbə & wintə & hində & tinkə & fingə \\
\hline b. & $-\mathrm{j}$ & ampjuwl & ambjələnt & kəntjuwz & hondju:rəs & vịkjələm & aygjələ \\
\hline c. & $\ldots \mathrm{w}$ & - & - & antwə:p & kondwit & baykwət & $\operatorname{laygwid}_{3}$ \\
\hline d. & $-r$ & emprəs & membrejn & entrij & həndrəd & siykrənij & aygrij \\
\hline e. & -1 & templə & embləm & antlə & t fa:ndlə & frayklin & ayglə \\
\hline f. & _\# & lamp & - & ant & hand & ink & - \\
\hline g. & $-\mathrm{n}$ & kəmpnij & - & sentnə & - & sblayknik & - \\
\hline h. & $-z$ & glimpz & - & $\mathrm{t} \int \mathrm{intzij}$ & - & svinkz & - \\
\hline i. & $-\mathrm{t}$ & emptij(?) & - & - & - & svinktə(?) & - \\
\hline
\end{tabular}

weakly. ${ }^{17}$ Another possibility, [mbt] and [ygt], results in an odd distribution: $[\mathrm{mb}]$ and $[\mathrm{gg}]$ are not available word finally, before a nasal or a fricative, but they would be before a plosive.

Let us suppose that we are not dealing with three-member clusters here at all, empty is [emtij] and sphincter is [svintə]. The excrescent plosive within the nonhomorganic nasal+plosive cluster is a phonetic phenomenon which is not subject to phonotactic constraints. Nasal+fricative clusters show parallel behaviour: warmth [wo:m $\langle\mathrm{p}\rangle \theta]$, Gimson [gim $\langle\mathrm{p}\rangle$ sən], infant [in $\langle\mathrm{t}\rangle$ fənt], length [ley $\langle\mathrm{k}\rangle \theta]$, youngster [jəy $\langle\mathrm{k}\rangle \mathrm{sd}$ ]. In the case of fricatives there is epenthesis also in homorganic clusters: symphony [sim $\langle\mathrm{p}\rangle$ fənij], anthem $\left.[\mathrm{an}\langle\mathrm{t}\rangle\rangle_{\partial \ni \mathrm{m}}\right]$, censor $\left[\operatorname{sen}\langle\mathrm{t}\rangle_{\mathrm{s} \partial}\right]$, censure $\left[\operatorname{sen}\langle\mathrm{t}\rangle \int \partial\right]$ (Wells 2008). Crucially, no epenthesis occurs before a lenis obstruent: triumvir [trajəm $\langle * \mathrm{~b}\rangle \mathrm{v}$ ], crimson $\left[\mathrm{krim}\left\langle{ }^{*} \mathrm{~b}\right\rangle \mathrm{z}\right.$ n], invalid $\left[\mathrm{in}\left\langle{ }^{*} \mathrm{~d}\right\rangle\right.$ vəlid], cleanser $\left[\mathrm{klen}\left\langle{ }^{*} \mathrm{~d}\right\rangle \mathrm{z} \mathrm{z}\right]$. In fact, earlier plosives, witnessed by the spelling, are lost in this position: Windsor [winzə], ambsace [ejmzejs]. We find just this situation in the case of alleged nasal+plosive+plosive clusters too: lambda [lamdə], Campden > Camden. So Hampden and Hampton are a minimal pair ([hamdən] vs. [hamtən]), with an excrescent plosive appearing before the fortis plosive, but not before the lenis one.

\section{Conclusions}

I have offered a rather unusual hypothesis about the identity of obstruent clusters in English, claiming that the most common type, FF, does not

17 There are also words with this cluster before a stressed vowel, e.g., tèmptátion or plànktónic. 
exist at all. This analysis solves a number of oddities: the overwhelming frequency of the marked laryngeal type in clusters, the curious absence of aspiration after fortis fricatives. In addition, it simplifies the allomorphy of the past tense and plural suffixes. All we have to dispense with is the idea that any phonetically voiceless obstruent is automatically fortis.

It must raise some suspicion though that this analysis goes against practically all earlier descriptions, like if everyone was driving in the wrong direction on the motorway. This seems to be a pedagogical lie: the transcriptions proposed here would lead many learners of English astray. Speakers of voicing languages with voice assimilation would misinterpret transcriptions like stop [sdop], box [bokz], or laughed [la:fd] as *[zdop], *[bogz], and *[la:vd] (in the last case the spelling is enough to mislead them). So we may take the [t] in [stop] to mean: "this is a [d], which, contrary to your expectations, does not make the preceding obstruent voiced."

\section{Acknowledgments}

This paper has benefitted from the comments of two anonymous reviewers and the two editors, disclaimers as usual. My work is partly sponsored by NKIFH grant \#119863. I am grateful to George Soros.

\section{References}

Backley, Phillip. 2011. An introduction to Element Theory. Edinburgh: Edinburgh University Press.

Balogné Bérces, Katalin and Bálint Huszthy. 2018. Laryngeal relativism predicts Italian. Yearbook of the Poznań Linguistic Meeting 4. 153-177.

Beckman, Jill, Michael Jessen and Catherine O. Ringen. 2013. Empirical evidence for laryngeal features: Aspirating vs. true voice languages. Journal of Linguistics 49. 259-284.

Blevins, Juliette. 1995. The syllable in phonological theory. In J. A. Goldsmith (ed.) The handbook of phonological theory. Cambridge, MA \& Oxford: Blackwell. 245-306.

Clements, George N. 1990. The role of the sonority cycle in core syllabification. In J. Kingston and M.E. Beckman (eds.) Papers in laboratory phonology I: Between the grammar and the physics of speech. Cambridge: Cambridge University Press. $283-333$.

Cruttenden, Alan. 2014. Gimson's pronunciation of English (8th edition). London \& New York: Routledge.

Cyran, Eugeniusz. 2014. Between phonology and phonetics. Polish voicing. Boston \& Berlin: De Gruyter Mouton.

Davidsen-Nielsen, Niels. 1969. English stops after initial /s/. English Studies 4. 321-339. 
G. Kiss, Zoltán. 2017. Aspiration of stops after fricatives in English: Results from a pilot experiment. In P. Szigetvári (ed.) 70 snippets to mark Ádám Nádasdy's 70th birthday. Budapest: Department of English Linguistics, Eötvös Loránd University. http://seas3.elte.hu/nadasdy70

Harris, John. 1994. English sound structure. Oxford \& Cambridge, MA: Blackwell.

Harris, John and Geoff Lindsey. 1995. The elements of phonological representation. In J. Durand and F. Katamba (eds.) Frontiers of phonology: Atoms, structures, derivations. Harlow: Longman. 34-79.

Honeybone, Patrick. 2002. Germanic obstruent lenition: Some mutual implications of theoretical and historical phonology. Doctoral dissertation. University of Newcastle upon Tyne.

Iverson, Gregory K. and Joseph C. Salmons. 1995. Aspiration and laryngeal representation in Germanic. Phonology 12. 369-396.

Jakobson, Roman, Gunnar Fant and Morris Halle. 1952. Preliminaries to speech analysis: The distinctive features and their correlates. Cambridge, MA: MIT Press.

Jansen, Wouter. 2004. Laryngeal contrast and phonetic voicing: A laboratory phonology approach to English, Hungarian, and Dutch. Doctoral dissertation. Rijksuniversiteit Groningen.

Jones, Daniel. 1967. The phoneme: Its nature and use (4th ed.). Cambridge: W. Heffer \& Sons.

Kahn, Daniel. 1976. Syllable-based generalisations in English phonology. Doctoral dissertation. MIT, Cambridge, MA. Published by Garland Press, New York, 1980.

Kaye, Jonathan. 2014. The Ins and Outs of phonology. In S. Bendjaballah, N. Faust, M. Lahrouchi and N. Lampitelli (eds.) The form of structure, the structure of form: Essays in honor of Jean Lowenstamm. Amsterdam \& Philadelphia: John Benjamins. 255-270.

Kaye, Jonathan D., Jean Lowenstamm and Jean-Roger Vergnaud. 1985. The internal structure of phonological elements: A theory of charm and government. Phonology Yearbook 2. 305-328.

Kim, Chin-Wu. 1970. A theory of aspiration. Phonetica 21. 107-116.

Lindsey, Geoff and Péter Szigetvári, 2013-. CUBE: Current British English searchable transcriptions. http://cubedictionary.org

Lowenstamm, Jean. 1981. On the maximal cluster approach to syllable structure. Linguistic Inquiry $12.575-604$.

Selkirk, Elisabeth O. 1984. On the major class features and syllable theory. In M. Aronoff and R. T. Oehrle (eds.) Language sound structure: Studies in phonology presented to Morris Halle by his teacher and students. Cambridge, MA: MIT Press. 107-136.

Sievers, Eduard. 1876. Grundzüge der Lautphysiologie zur Einführung in das Studium der Lautlehre der 309 indogermanischen Sprachen. Leipzig: Beitkopf und Härtel.

Twaddell, W. Freeman. 1935. On defining the phoneme. Language 11. 5-62.

Wells, John C. 2008. Longman pronunciation dictionary (3rd ed.). Harlow: Pearson/Longman.

Zec, Draga. 1995. Sonority constraints on syllable structure. Phonology 12. 85-129. 
Open Access. This is an open-access article distributed under the terms of the Creative Commons Attribution 4.0 International License (https://creativecommons.org/licenses/ by/4.0), which permits unrestricted use, distribution, and reproduction in any medium, provided the original author and source are credited, a link to the CC License is provided, and changes - if any - are indicated. (SID_1) 